\title{
A comparative study of bifidobacteria in human babies and adults
}

\author{
Shadi KHONSARI ${ }^{1}$, Mayuran SUGANTHY ${ }^{1}$, Beata BURCZYNSKA ${ }^{1}$, Vu DANG, Manika CHOUDHURY ${ }^{1}$ and \\ Azra PACHENARI ${ }^{1 *}$
}

${ }^{1}$ School of Science and Technology, Middlesex University, Town Hall The Burroughs, Hendon, London NW4 4BT, UK

Received May 21, 2015; Accepted December 9, 2015; Published online in J-STAGE December 26, 2015

The composition and diversity of the gut microbiota are known to be different between babies and adults. The aim of this project was to compare the level of bifidobacteria between babies and adults and to investigate the influence of lifestyle factors on the level of this bacterium in the gut. During this study, the levels of bifidobacteria in 10 human babies below 2 years of age were compared with that of 10 human adults above 40 years. The level of bifidobacteria proved to be significantly higher in babies in comparison with adults. This investigation concluded that a combination of several factors, such as age, diet, and BMI, has an important effect on the level of bifidobacteria in adults, while in babies, a combination of diet and age may influence the level of intestinal bifidobacteria.

Key words: bifidobacteria, gut microbiota, age

Although swallowing of amniotic fluid by the fetus has been suggested to be a prenatal source of microorganisms that colonize the GI tract [1], actual colonization starts during and after birth, with the source of the microorganisms being the mother's fecal and vaginal bacteria, food, the environment, skin contact with other humans, and air [2, 3]. Facultative bacteria such as streptococci, staphylococci, enterococci, and Enterobacteriaceae are the first to colonize the gut due to the presence of a high level of oxygen, but as the level of oxygen is reduced by these microorganisms, the gut environment becomes more favorable for growth of anaerobes such as bifidobacteria, Bacteroides, and clostridia [4, 5]. Two major determinants of the early composition of the gut microbiota are mode of delivery and digestion of breast or formula milk. However, it should be mentioned that currently most baby formulas contain prebiotic compounds that enhance growth of bifidobacteria. During this study, 3 out of ten babies were confirmed to be receiving formula milk containing prebiotics. One baby consumed formula milk that did not contain prebiotics, and no information is available

\footnotetext{
*Corresponding author. Mailing address: Azra Pachenari, School of Science and Technology, Middlesex University, Town Hall, The Burroughs, Hendon, London NW4 4BT, UK. Phone: $+44-20$ 8411 5115. E-mail: a.pachenari@mdx.ac.uk

(C)2016 BMFH Press

This is an open-access article distributed under the terms of the Creative Commons Attribution Non-Commercial No Derivatives (bync-nd) License $<$ http://creativecommons.org/licenses/by-nc-nd/4.0/>.
}

on formula milk consumed by other babies (Table 1). Microorganisms enter the newborn's gastrointestinal tract from mother's vaginal and perianal areas [6]. Similar microbial populations are seen in mothers and their infants when infants are delivered vaginally [7]. Caesarean delivery on the other hand deprives the newborn of the mother's vaginal and fecal microbiota. Chen et al. compared the levels of bifidobacteria and lactobacilli in breast-fed infants who were born vaginally with those of breast-fed infants born by caesarean section and showed that infants that were born vaginally had higher populations of both bifidobacteria and lactobacilli, and they concluded that the population of bifidobacteria was more disturbed than that of lactobacilli in infants that were born by caesarean section [8]. Mother's milk provides a source of growth factors for bifidobacteria in the gut, which results in an increased population of beneficial bacteria in newborn babies, and it is also suggested to harbor these bacteria [9-12]. As the infant ages, the gut microbiota matures, and its diversity increases. It is not known at what age exactly the adult microbiota is established, but some studies suggest that after 2 years of age, the gut microbiota becomes more adult-like [13, 14]. A significantly higher diversity in gut microbiota is shown in adults older than 20 years of age in comparison with children of between 1 to 4 years of age, while a higher level of bifidobacteria is reported in children in comparison with adults [15]. Hopkins et al. compared the gut microbiota in children who were 16 months to 7 years of age, adults who were 21 to 34 years 
Table 1. Details of the babies shown in order of level of bifidobacteria (lowest to highest). Results are shown as the average of triplet plates and three experiments

\begin{tabular}{|c|c|c|c|c|c|c|c|c|c|}
\hline Subject & Age (years) & Gender & Infant $\mathrm{CFU} / \mathrm{g}^{-1}$ & Weight $(\mathrm{kg})$ & Birth mode* & Breast milk & Formula & Prebiotics & Solid food \\
\hline Baby 1 & 1.66 & Female & $3 \pm 8.62 \times 10^{9}$ & 11.453 & $\mathrm{~V}$ & 0 & 1 & & 1 \\
\hline Baby 2 & 1 & Female & $3.4 \pm 0.65 \times 10^{9}$ & 11 & V & 0 & 1 & 0 & 1 \\
\hline Baby 3 & 1.5 & Female & $6.73 \pm 0.2 \times 10^{9}$ & 10.7 & V & 0 & 1 & & 1 \\
\hline Baby 4 & 1.17 & Male & $1 \pm 0.27 \times 10^{10}$ & 12 & $\mathrm{C}$ & 0 & 1 & 1 & 1 \\
\hline Baby 5 & 1.66 & Male & $1.02 \pm 0.3 \times 10^{10}$ & 11.54 & $\mathrm{C}$ & 1 & 1 & & 1 \\
\hline Baby 6 & 0.66 & Male & $1.12 \pm 0.21 \times 10^{10}$ & 8 & V & 1 & 0 & & 1 \\
\hline Baby 7 & 1 & Male & $1.37 \pm 0.5 \times 10^{10}$ & 11 & $\mathrm{C}$ & 1 & 1 & 1 & 1 \\
\hline Baby 8 & 0.42 & Male & $2 \pm 0.74 \times 10^{10}$ & 5.5 & $\mathrm{C}$ & 1 & 1 & 1 & 1 \\
\hline Baby 9 & 1.33 & Male & $8.36 \pm 13.05 \times 10^{10}$ & 10.75 & $\mathrm{C}$ & 0 & 1 & & 1 \\
\hline Baby 10 & 1 & Male & $2.8 \pm 9.6 \times 10^{11}$ & 10.047 & V & 1 & 1 & & 1 \\
\hline
\end{tabular}

*Birth mode: V: vaginal birth, C: caesarean. Breast milk, formula, prebiotics, solid food: 0: not part of diet, 1: part of diet.

of age, and elderly subjects who were 67 to 88 years of age, and reported decreased species diversity and decreased level of bifidobacteria in the elderly group [16]. It is suggested that the changes in gut microbiota associated with aging are due to a decrease in adaptive capacity of the gastrointestinal tract and delayed recovery from illnesses and health conditions [17].

The aim of this study was to quantify and compare the population of bifidobacteria in fecal samples from infants who were less than 2 years of age and adults who were above 40 years of age. The impact of diet, body mass index (BMI), smoking, and drinking on the level of bifidobacteria in adults and effect of diet and mode of delivery on bifidobacteria in babies were also investigated.

Ten healthy adults who were over 40 years of age were selected to participate in the study. The subjects maintained their normal lifestyles, did not consume probiotic or prebiotic products for one month before and during the study apart from their routine yoghurt consumption, did not receive any kind of antibiotic or medication that may affect the composition of the gut microbiota for one month before and during the study, did not suffer from any kind of GI tract disease that may affect the gut microbiota, and did not consume alcohol for one month before and during the course of study. Five of the 10 adults were smokers, none were regular alcohol drinkers, and one did not drink at all. When vegetables, fruit, rice, and yoghurt were consumed by participants more than three times a week, they were considered a "regular part of their diet", and when these types of food were consumed less than three times a week, they were considered a "part of their diet" (Table 2). Ten healthy babies who were less than 2 years of age were selected for participation in the study. They did not receive any kind of antibiotic or medication that may affect the composition of the gut microbiota for one month before and during the study, were born vaginally or by caesarean section, and were bottle or breast-fed (Table 1).

Adult participants were provided with sterile containers for collection of fecal samples, and samples from babies were collected from their diapers by sterile spatula. Specimens were transferred to the microbiology laboratory of Middlesex University within two hours after collection and serially diluted in PBS containing $0.5 \mathrm{~g} / 1$ of cysteine hydrochloride. One hundred microliters of each dilution was transferred to triplet plates of BIM-25 and incubated anaerobically at $37^{\circ} \mathrm{C}$ for 72 hours [18]. This procedure was repeated three times for each participant.

Two colony types grew on every plate: colonies that were pink with a red centre, and pure red colonies. Twenty representatives of each colony type were purified on reinforced clostridial medium (RCM) for identification.

Identification of colonies was achieved by Gram staining, direct colony PCR, and Martix-Assisted Laser Desorption/Ionization Time-of-Flight (MALDI-TOF) Biotyper (Autoflex, Bruker).

Primers designed for 16S rRNA of genus Bifidobacterium, Bifidobacterium longum group (B. longum and Bifidobacterium infantis), and B. longum species (Table 3) were used for amplification of the target gene by direct colony PCR for all isolates based on the conditions recommended by Matsuki et al. [19-21]. No template controls (NTCs) as well as a positive control (B. longum NTCC 8809) were included in the analysis with genus-, group-, and species- targeted primers. PCR products were analyzed using an MCE-202 MultiNa Microchip Electrophoresis System (Shimadzu, Japan) and DNA-1000 reagent kit according to the manufacturer's instructions. Typical results are shown in Fig. 1.

Twenty isolates that were identified by the PCR method were further confirmed by MALDI-TOF as 
Table 2. Details of the adults shown in order of level of bifidobacteria (lowest to highest). Results are shown as the average of triplet plates and three experiments

\begin{tabular}{|c|c|c|c|c|c|c|c|c|c|}
\hline Subject & Age (years) & Gender & Adult $\mathrm{CFU} / \mathrm{g}^{-1}$ & Adult BMI & Smoking & Alcohol & Meat* & Fruit \& Veg* & Yoghurt* \\
\hline Adult 1 & 65 & Male & $1.3 \pm 4.68 \times 10^{6}$ & 30 & $\mathrm{Y}$ & $\mathrm{Y}$ & 1 & 1 & 1 \\
\hline Adult 2 & 48 & Male & $7 \pm 63 \times 10^{6}$ & 31 & $\mathrm{Y}$ & $\mathrm{Y}$ & 1 & 1 & 1 \\
\hline Adult 3 & 43 & Male & $7 \pm 9.5 \times 10^{6}$ & 29 & $\mathrm{Y}$ & $\mathrm{Y}$ & 1 & 1 & 1 \\
\hline Adult 4 & 43 & Female & $9.43 \pm 4.11 \times 10^{7}$ & 23 & $\mathrm{Y}$ & $\mathrm{Y}$ & 1 & 2 & 2 \\
\hline Adult 5 & 52 & Male & $2.37 \pm 5.2 \times 10^{8}$ & 20 & $\mathrm{~N}$ & $\mathrm{Y}$ & 1 & 2 & 2 \\
\hline Adult 6 & 42 & Male & $2.47 \pm 3.1 \times 10^{8}$ & 24 & $\mathrm{~N}$ & $\mathrm{Y}$ & 1 & 2 & 2 \\
\hline Adult 7 & 41 & Female & $4.1 \pm 1.54 \times 10^{8}$ & 22 & $\mathrm{Y}$ & $\mathrm{Y}$ & 1 & 2 & 2 \\
\hline Adult 8 & 60 & Male & $1.49 \pm 0.3 \times 10^{9}$ & 30 & $\mathrm{~N}$ & $\mathrm{Y}$ & 1 & 2 & 0 \\
\hline Adult 9 & 65 & Male & $2.5 \pm 0.6 \times 10^{9}$ & 27 & $\mathrm{~N}$ & $\mathrm{Y}$ & 1 & 2 & 0 \\
\hline Adult 10 & 58 & Female & $5.26 \pm 0.91 \times 10^{9}$ & 21 & $\mathrm{~N}$ & $\mathrm{~N}$ & 1 & 2 & 2 \\
\hline
\end{tabular}

*Meat, fruit, vegetable and yoghurt: 0: not part of diet, 1: part of diet (less than 3 times per week), 2: regular part of diet (more than 3 times per week)

Table 3. Primers used for $16 \mathrm{~S}$ rDNA colony PCR

\begin{tabular}{llll}
\hline \multicolumn{1}{c}{ Target bacteria } & \multicolumn{1}{c}{ Primer } & \multicolumn{1}{c}{ Sequence } & Reference \\
\hline Bifidobacterium spp. & g-Bifid-F & CTCCTGGAAACGGGTGG & \\
& g-Bifid-R & GGTGTTCTTCCCGATATCTACA & (Matsuki et al., 2002) \\
Bifidobacterium longum group & BiLON-1A & TTCCAGTTGATCGCATGGTC & \\
& BiLON-2A & TCSCGCTTGCTCCCCGAT & (Matsuki et al., 1998) \\
Bifidobacterium longum & BiLON-1B & TTCCAGTTGATCGCATGGTC & \\
& BiLON-2B & GGGAAGCCGTATCTCTACGA & (Matsuki et al., 1999) \\
\hline
\end{tabular}

B. longum using the formic acid extraction method. The acquired mass spectra in the flex control method were compared to reference spectra using the Biotyper RTC software, allowing identification of microorganism down to the genus and species level based on the Bruker score system [22-24].

The twenty isolates of bifidobacteria were cultured on reinforced clostridial agar and incubated anaerobically at $37^{\circ} \mathrm{C}$ for $48 \mathrm{hr}$. Single colonies were transferred to $1.5 \mathrm{ml}$ tubes in duplicate with $300 \mu$ l of deionized water and mixed thoroughly. Nine hundred microliters of absolute ethanol was then added, samples were vortexed and centrifuged at 13,500 rpm for $2 \mathrm{~min}$ at room temperature. The supernatant and all residual ethanol was removed, and samples were dried at room temperature for 5 minutes. Proteins were extracted using $20 \mu 1$ of $70 \%$ formic acid and an equal volume of pure acetonitrile $(\mathrm{ACN})$. Samples were then centrifuged at maximum speed, and $1 \mu \mathrm{l}$ of supernatant was pipetted into a MALDI target plate (MTP MSP 48 Polished Steel) and allowed to dry at room temperature for 30 minutes. Each spot was overlaid with $1 \mu 1$ of freshly prepared HCCA matrix solution. The matrix used for spotting contained $10 \mathrm{mg} / \mathrm{ml}$ of HCCA ( $\alpha$-Cyano-4-hydroxycinnamic acid butylamine salt) (Sigma) in standard solvent (acetonitrile
$50 \%$, deionized water $47.5 \%$, trifluoroacetic acid $2.5 \%$ ) (Sigma). One microliter of Bruker Bacterial Test Standard (BTS, Bruker) was used for calibration $[25,26]$.

Data analysis was carried out using Minitab 16.2.4 (Minitab Inc., State College PA, USA). The data sets included in this study were age (years); gender; adult BMI; adult smokers; adult drinkers; adult diet in terms of consumption of meat, fibre, and yoghurt; baby weight (kg); birth mode; and baby diet in terms of consumption of breast milk, formula milk, prebiotics, and solid food (Tables 1 and 2). Before statistical analysis, normality tests were conducted on all data sets to determine the normality of their distributions. The Mann-Whitney test was used to investigate whether there was a significant difference in the population of bifidobacteria $\left(\mathrm{CFU} / \mathrm{g}^{-1}\right)$ between the adult and infant samples, as well as to test for differences in the level of bifidobacteria and diet within each age group; differences due to smoking and drinking alcohol were also tested for in adults, and birth mode was tested for differences in infants. Spearman's rank correlation was used to investigate relationships between level of bifidobacteria $\left(\mathrm{CFU} / \mathrm{g}^{-1}\right)$ and age within both the adult and infant groups independently and collectively. Infant weight and adult BMI were also correlated using Spearman's rank correlation. All tests were conducted 

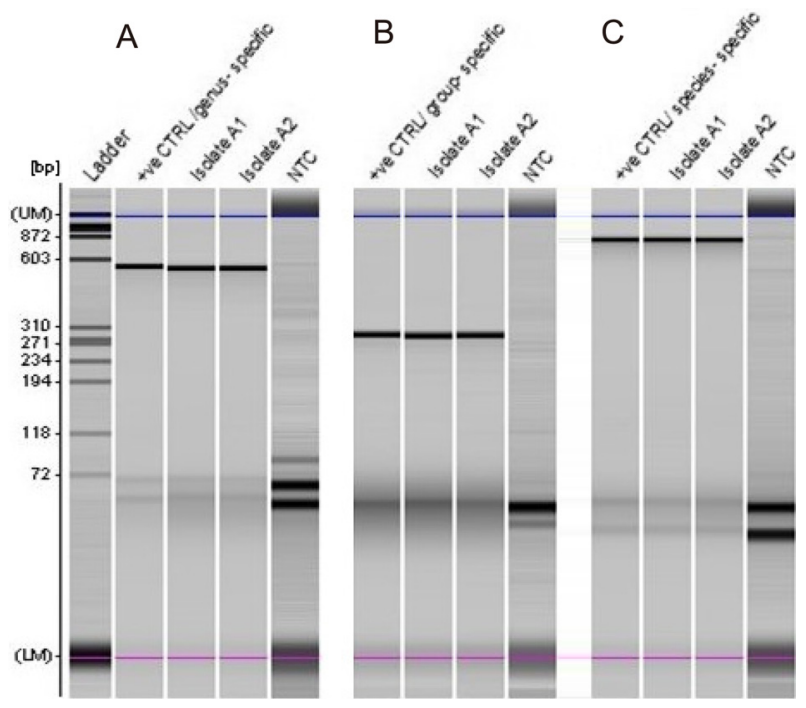

Fig. 1. Electropherogram of direct colony PCR products separated by an MCE-202 MultiNa Microchip Electrophoresis System with a DNA-1000 kit (Shimadzu).

Representation of positive isolates $\mathrm{A} 1$ and $\mathrm{A} 2$, which were amplified with three sets of primers for identification at the genus and species levels. Panel A: Bifidobacterium genus-specific primers were used, and $510 \mathrm{bp}$ products were detected for isolates and the positive control (+ve CTRL). Panel B: Bifidobacterium group primers were used, and 277 bp products were detected. Panel C: species-specific primers were used, and 831 bp products were amplified. The positive control used for all reactions was $B$. longum (NCTC 8809). The position of the upper (UM) and lower (LM) marker dyes of the MultiNA separation are indicated as is the position of the base pair reference mass markers; bands below 72 bp correspond to primers. The ladder (PhiX174 DNA/Hae III, Promega) showed separate bands between $72 \mathrm{bp}$ and $872 \mathrm{bp}$. No template controls (NTCs) are shown for three sets of reactions.

with a $95 \%$ confidence interval $(\alpha=0.05)$.

All pink colonies with a red centre showed successful amplification of the 16S rRNA gene of Bifidobacterium at the genus and species level (Fig. 1). A 510 bp product was amplified with genus-specific primers when $B$. longum (ACC No. CP010453) was used as a template. $B$. longum group primers resulted in amplification of a 277 bp product for all isolates, and this result was confirmed by colony PCR using species-specific primers, which showed amplification of $831 \mathrm{bp}$ for 16S rRNA of $B$. longum.

All 20 isolates were identified to the species level as B. longum, $75 \%$ with $\log$ (score) $\geq 2$ and $25 \%$ with $\log$ (score) $<2$ and $\geq 1.7$ by Biotyper MALDI-TOF MS.

Results of enumeration of colonies of bifidobacteria are shown in Fig. 2 and Tables 1 and 2.

During this study, intraindividual variation in the population of bifidobacteria in adults and babies was

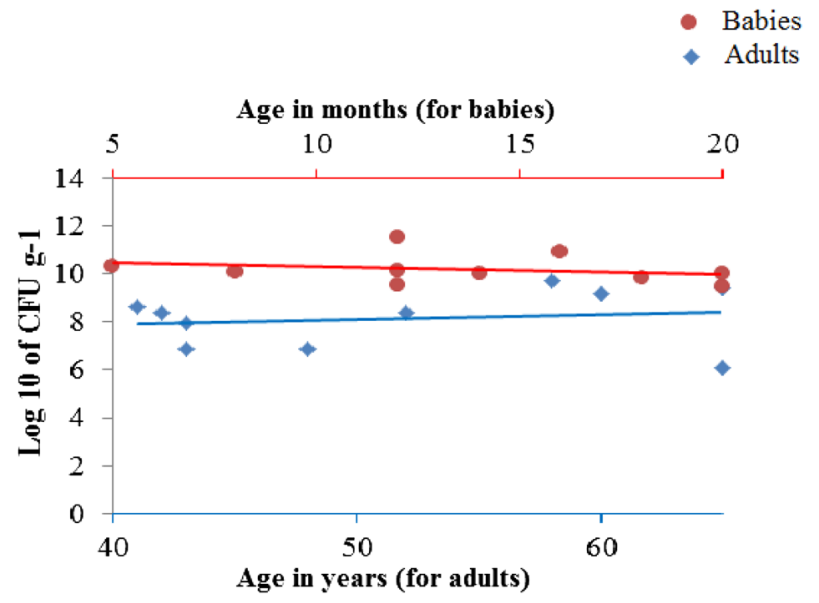

Fig. 2. Results of enumeration of colonies of bifidobacteria in babies and adults.

observed that could be due to variations in diet or other daily activities. Significant intraindividual variation in the population of bifidobacteria and hydrogen sulfideproducing bacteria was shown in adults in a previous study by Pachenari et al. [27].

A significant difference was observed in the population of bifidobacteria in babies in comparison with adults. Adults had a median population of $2.42 \times 10^{8} \mathrm{CFU} / \mathrm{g}^{-1}$, while infants had a median population of $1.07 \times 10^{10}$ $\mathrm{CFU} / \mathrm{g}^{-1}(\mathrm{p}<0.05)$ (Tables 1 and 2$)$.

Reduction in intestinal bifidobacteria and a shift in composition of species of bifidobacteria in the gut in adults have been observed by other investigators [15, $16,21]$. It is suggested that this reduction may be due to a decreased ability of bifidobacteria to adhere to older intestinal mucosal cells [28] as well as delayed recovery from illnesses and health conditions in the elderly [17].

Adults had a mean bifidobacteria population of $1.03 \pm$ $1.7 \times 10^{9} \mathrm{CFU} / \mathrm{g}^{-1}$, while infants had a mean bifidobacteria population of $4.4 \pm 8.6 \times 10^{10} \mathrm{CFU} / \mathrm{g}^{-1}$ (Tables 1 and 2). No significant correlation was seen between the age of infants and their levels of bifidobacteria in our study $(\mathrm{p}=0.16, r=-0.47)$. However, when infants and adults were analyzed collectively, a significant correlation was seen $(\mathrm{p}<0.05, r=-0.77)$ between age (years) and the level of intestinal bifidobacteria. No significant correlation was observed between age of adults and their level of intestinal bifidobacteria $(\mathrm{p}=0.68, \mathrm{r}=0.15)$.

Recent studies showed a lower level of bifidobacteria in people with a vegan or vegetarian diet in comparison with control subjects [29, 30]. However, a higher population of bifidobacteria was found in subjects who 
consumed a higher amount of rice [31]. The results of the present study showed that those participants who reported consuming fruit and vegetables more than three times per week had on average a larger population of bifidobacteria (median $=4.1 \times 10^{8} \mathrm{CFU} / \mathrm{g}^{-1}$ ) than those who reported consuming these types of food less than three times a week $\left(\right.$ median $\left.=7 \times 10^{6} \mathrm{CFU} / \mathrm{g}^{-1}\right)$, which indicates a significant difference between the two groups $(\mathrm{p}<0.05)$.

Ley et al. reported that the levels of bifidobacteria and lactobacilli were lower in overweight people than slim individuals [32]. An increase in intestinal bifidobacteria brought about by weight loss has been reported by de Silva et al. [33]. In addition, an investigation using mice showed that a high-fat diet decreased the population of bifidobacteria around 100-fold and increased fat tissue, liver triglycerides, and endotoxemia [34]. In the present study, the correlation between adult BMI and population of bifidobacteria seemed to suggest a reinforcement of trends found in previous literature $(\mathrm{p}=0.16, r=-0.48)$, although not significant, the results are not far from being significant and may be verified with a larger sample size. Nevertheless, other factors such as diet, age, and eating/ smoking habits could have also influenced the findings.

Tomoda et al. suggested that smoking may reduce the level of beneficial bacteria in the gut [35]. In the present study, a significant difference in level of bifidobacteria was observed between smokers and nonsmokers $(\mathrm{p}<0.05)$, with nonsmokers having a higher median level of bifidobacteria $\left(1.49 \times 10^{9} \mathrm{CFU} / \mathrm{g}^{-1}\right)$ than smokers $\left(7 \times 10^{6} \mathrm{CFU} / \mathrm{g}^{-1}\right)$.

It has been shown that infants born vaginally have a higher level of bifidobacteria than infants born by caesarean section [8] but that the level reaches that of vaginally born babies at one month of age [36, 37]. In our study, the highest and lowest levels of bifidobacteria were shown in babies 10 and 1, respectively, both of whom were born vaginally. The second and third highest levels of bifidobacteria were seen in baby 9 and baby 8 , who were both born by caesarean section. However, all the babies had passed the age (one month) at which an impact of method of delivery may be shown on their intestinal bifidobacteria, and therefore no significant difference was seen in the population of bifidobacteria in infants when they were divided according to mode of birth $(\mathrm{p}=0.3)$. Interestingly, those born by caesarean section had a higher median of level of bifidobacteria $\left(1.37 \times 10^{10}\right.$ $\left.\mathrm{CFU} / \mathrm{g}^{-1}\right)$; than those born vaginally $\left(6.73 \times 10^{9} \mathrm{CFU} /\right.$ $\mathrm{g}^{-1}$ ); however, this may have been affected by the infants' age and diet.

Presence of a higher population of bifidobacteria in breast-fed babies has been established [38, 39]. This in part may be due to bifidogenic factors such as $\mathrm{N}$-acetyl-glucosamine, lactulose, and other human milk oligosaccharides in human milk [40, 41]. In addition breast milk itself has been shown to be a source of microorganisms such as staphylococci, lactic acid bacteria, and bifidobacteria, which enhance development of a healthy gut microbiota in infants [42-47]. Nonetheless, this level reduces as the baby ages [48]. Although the difference in population of bifidobacteria among breast-fed and bottle-fed babies was not significant $(\mathrm{p}=0.09)$, the data do show a higher population of bifidobacteria in infants who had breast milk as part of their diet, with their median population being $1.37 \times 10^{10} \mathrm{CFU} / \mathrm{g}^{-1}$, compared with those who did not, with their median population being $6.73 \times 10^{9} \mathrm{CFU} /$ $\mathrm{g}^{-1}$. The significance of these results may be confounded by the age of the infants.

However, it should be noted that other factors that were not included in this study may also have affected the level of intestinal bifidobacteria in this study.

This report concluded that not one but a combination of several factors affect the level of bifidobacteria in the gut. In our adult samples, a combination of age, level of dietary fibre intake, BMI, and smoking influenced the levels of bifidobacteria, while in our baby samples, consumption of breast/bottle milk, and age suggested a possible trend that was consistent with previous findings. However, large-scale longitudinal studies are needed to validate these findings.

\section{REFERENCES}

1. Fouhy F, Ross RP, Fitzgerald GF, Stanton C, Cotter PD. 2012. Composition of the early intestinal microbiota: knowledge, knowledge gaps and the use of high-throughput sequencing to address these gaps. Gut Microbes 3: 203-220. [Medline] [CrossRef]

2. Adlerberth I, Wold AE. 2009. Establishment of the gut microbiota in Western infants. Acta Paediatr 98: 229-238. [CrossRef] [Medline]

3. Putignani L. 2012. Human gut microbiota: onset and shaping through life stages and perturbations. Front Cell Infect Microbiol 2: 144. [Medline] [CrossRef]

4. Vael C, Desager K. 2009. The importance of the development of the intestinal microbiota in infancy. Curr Opin Pediatr 21: 794-800. [Medline] [CrossRef]

5. Sjöberg F, Nowrouzian F, Rangel I, Hannoun C, Moore E, Adlerberth I, Wold AE. 2013. Comparison between terminal-restriction fragment length polymorphism (T-RFLP) and quantitative culture for analysis of infants' gut microbiota. J Microbiol Methods 94: 37-46. [Medline] [CrossRef]

6. Fanaro S, Chierici R, Guerrini P, Vigi V. 2003. 
Intestinal microflora in early infancy: composition and development. Acta Paediatr Suppl 91 s441: 48-55. [Medline]

7. Mändar R, Mikelsaar M. 1996. Transmission of mother's microflora to the newborn at birth. Biol Neonate 69: 30-35. [Medline] [CrossRef]

8. Chen J, Cai W, Feng Y. 2007. Development of intestinal bifidobacteria and lactobacilli in breast-fed neonates. Clin Nutr 26: 559-566. [Medline] [CrossRef]

9. Zivkovic AM, German JB, Lebrilla CB, Mills DA. 2011. Human milk glycobiome and its impact on the infant gastrointestinal microbiota. Proc Natl Acad Sci USA 108 Suppl 1: 4653-4658. [Medline] [CrossRef]

10. Marcobal A, Sonnenburg JL. 2012. Human milk oligosaccharide consumption by intestinal microbiota. Clin Microbiol Infect 18 Suppl 4: 12-15. [Medline] [CrossRef]

11. Fernández L, Langa S, Martín V, Maldonado A, Jiménez E, Martín R, Rodríguez JM. 2013. The human milk microbiota: origin and potential roles in health and disease. Pharmacol Res 69: 1-10. [Medline] [CrossRef]

12. Grönlund MM, Gueimonde M, Laitinen K, Kociubinski G, Grönroos T, Salminen S, Isolauri E. 2007. Maternal breast-milk and intestinal bifidobacteria guide the compositional development of the Bifidobacterium microbiota in infants at risk of allergic disease. Clin Exp Allergy 37: 1764-1772. [Medline] [CrossRef]

13. Palmer C, Bik EM, DiGiulio DB, Relman DA, Brown PO. 2007. Development of the human infant intestinal microbiota. PLoS Biol 5: e177. [Medline] [CrossRef]

14. Wall R, Ross RP, Ryan CA, Hussey S, Murphy B, Fitzgerald GF, Stanton C. 2009. Role of gut microbiota in early infant development. Clin Med Pediatr 3: 45-54. [Medline]

15. Ringel-Kulka T, Cheng J, Ringel Y, Salojärvi J, Carroll I, Palva A, de Vos WM, Satokari R. 2013. Intestinal microbiota in healthy U.S. young children and adults - a high throughput microarray analysis. PLoS ONE 8: e64315. [CrossRef] [Medline]

16. Hopkins MJ, Sharp R, Macfarlane GT. 2001. Age and disease related changes in intestinal bacterial populations assessed by cell culture, 16S rRNA abundance, and community cellular fatty acid profiles. Gut 48: 198-205. [Medline] [CrossRef]

17. Salles N. 2007. Basic mechanisms of the aging gastrointestinal tract. Dig Dis 25: 112-117. [Medline] [CrossRef]

18. Muñoa FJ, Pares R. 1988. Selective medium for isolation and enumeration of Bifidobacterium spp. Appl Environ Microbiol 54: 1715-1718. [Medline]

19. Matsuki T, Watanabe K, Tanaka R, Oyaizu H. 1998. Rapid identification of human intestinal bifidobacteria by $16 \mathrm{~S}$ rRNA-targeted species- and group-specific primers. FEMS Microbiol Lett 167: 113-121. [Medline] [CrossRef]
20. Matsuki T, Watanabe K, Tanaka R, Fukuda M, Oyaizu H. 1999. Distribution of bifidobacterial species in human intestinal microflora examined with $16 \mathrm{~S}$ rRNAgene-targeted species-specific primers. Appl Environ Microbiol 65: 4506-4512. [Medline]

21. Matsuki T, Watanabe K, Fujimoto J, Miyamoto Y, Takada T, Matsumoto K, Oyaizu H, Tanaka R. 2002. Development of $16 \mathrm{~S}$ rRNA-gene-targeted groupspecific primers for the detection and identification of predominant bacteria in human feces. Appl Environ Microbiol 68: 5445-5451. [Medline] [CrossRef]

22. Sogawa K, Watanabe M, Sato K, Segawa S, Ishii C, Miyabe A, Murata S, Saito T, Nomura F. 2011. Use of the MALDI BioTyper system with MALDITOF mass spectrometry for rapid identification of microorganisms. Anal Bioanal Chem 400: 1905-1911. [Medline] [CrossRef]

23. Angelakis E, Million M, Henry M, Raoult D. 2011. Rapid and accurate bacterial identification in probiotics and yoghurts by MALDI-TOF mass spectrometry. J Food Sci 76: M568-M572. [Medline] [CrossRef]

24. Ruiz-Moyano S, Tao N, Underwood MA, Mills DA. 2012. Rapid discrimination of Bifidobacterium animalis subspecies by matrix-assisted laser desorption ionization-time of flight mass spectrometry. Food Microbiol 30: 432-437. [Medline] [CrossRef]

25. Panda A, Kurapati S, Samantaray JC, Srinivasan A, Khalil S. 2014. MALDI-TOF mass spectrometry proteomic based identification of clinical bacterial isolates. Indian J Med Res 140: 770-777. [Medline]

26. Nagy E, Becker S, Kostrzewa M, Barta N, Urbán E. 2012. The value of MALDI-TOF MS for the identification of clinically relevant anaerobic bacteria in routine laboratories. J Med Microbiol 61: 1393-1400. [CrossRef] [Medline]

27. Pachenari A, Akanni T, Busta FF, Brady LJ. 1999 Inter and intra-individual variation in population of bifidobacteria and hydrogen sulphide producing bacteria in feces of five healthy individuals. Paper 37D18 presented at the 1999 Annual Meeting of the Institute of Food Technologists, Chicago, IL, July 23-27, 1999.

28. He F, Ouwehand AC, Isolauri E, Hosoda M, Benno Y, Salminen S. 2001. Differences in composition and mucosal adhesion of bifidobacteria isolated from healthy adults and healthy seniors. Curr Microbiol 43: 351-354. [Medline] [CrossRef]

29. Zimmer J, Lange B, Frick JS, Sauer H, Zimmermann K, Schwiertz A, Rusch K, Klosterhalfen S, Enck P. 2012. A vegan or vegetarian diet substantially alters the human colonic faecal microbiota. Eur J Clin Nutr 66: 53-60. [CrossRef] [Medline]

30. Enck P, Lange B, Zimmer J, Zimmermann K, Klosterhalfen S, Frick JS. 2009. Maintaining a strict vegan or vegetarian diet changes the colonic microflora. Z Gastroenterol 47: 163. [CrossRef]

31. Fernando WM, Flint S, Zou M, Brennan CS, Ranaweera 
KK, Bamunuarachchi A. 2011. The effect of rice fibre fractions on the growth of co-cultures of probiotics. J Food Sci Technol 48: 14-25. [Medline] [CrossRef]

32. Ley RE, Bäckhed F, Turnbaugh P, Lozupone CA, Knight RD, Gordon JI. 2005. Obesity alters gut microbial ecology. Proc Natl Acad Sci USA 102: 11070-11075. [Medline] [CrossRef]

33. da Silva ST, dos Santos CA, Bressan J. 2013. Intestinal microbiota; relevance to obesity and modulation by prebiotics and probiotics. Nutr Hosp 28: 1039-1048. [Medline]

34. Clarke SF, Murphy EF, Nilaweera K, Ross PR, Shanahan F, O'Toole PW, Cotter PD. 2012. The gut microbiota and its relationship to diet and obesity: new insights. Gut Microbes 3: 186-202. [Medline] [CrossRef]

35. Tomoda K, Kubo K, Asahara T, Andoh A, Nomoto K, Nishii Y, Yamamoto Y, Yoshikawa M, Kimura H. 2011. Cigarette smoke decreases organic acids levels and population of bifidobacterium in the caecum of rats. $\mathrm{J}$ Toxicol Sci 36: 261-266. [Medline] [CrossRef]

36. Salminen S, Gibson GR, McCartney AL, Isolauri E. 2004. Influence of mode of delivery on gut microbiota composition in seven year old children. Gut 53: 13881389. [Medline] [CrossRef]

37. Grönlund MM, Lehtonen OP, Eerola E, Kero P. 1999. Fecal microflora in healthy infants born by different methods of delivery: permanent changes in intestinal flora after cesarean delivery. J Pediatr Gastroenterol Nutr 28: 19-25. [Medline] [CrossRef]

38. Roger LC, Costabile A, Holland DT, Hoyles L, McCartney AL. 2010. Examination of faecal Bifidobacterium populations in breast- and formula-fed infants during the first 18 months of life. Microbiology 156: 3329-3341. [Medline] [CrossRef]

39. Heavey P, Rowland IR. 1999. The gut microflora of the developing infant: microbiology and metabolism. Microb Ecol Health Dis 11: 75-83. [CrossRef]

40. Coppa GV, Bruni S, Morelli L, Soldi S, Gabrielli O. 2004. The first prebiotics in humans: human milk oligosaccharides. J Clin Gastroenterol 38 Suppl: S80-
S83. [Medline] [CrossRef]

41. Bode L. 2009. Human milk oligosaccharides: prebiotics and beyond. Nutr Rev 67 Suppl 2: S183S191. [Medline] [CrossRef]

42. Martín R, Langa S, Reviriego C, Jimínez E, Marín ML, Xaus J, Fernández L, Rodríguez JM. 2003. Human milk is a source of lactic acid bacteria for the infant gut. J Pediatr 143: 754-758. [Medline] [CrossRef]

43. Martín R, Heilig HGHJ, Zoetendal EG, Jiménez E, Fernández L, Smidt H, Rodríguez JM. 2007. Cultivation-independent assessment of the bacterial diversity of breast milk among healthy women. Res Microbiol 158: 31-37. [Medline] [CrossRef]

44. Martín R, Heilig GH, Zoetendal EG, Smidt H, Rodríguez JM. 2007. Diversity of the Lactobacillus group in breast milk and vagina of healthy women and potential role in the colonization of the infant gut. $\mathrm{J}$ Appl Microbiol 103: 2638-2644. [Medline] [CrossRef]

45. Martín R, Jiménez E, Heilig H, Fernández L, Marín ML, Zoetendal EG, Rodríguez JM. 2009. Isolation of bifidobacteria from breast milk and assessment of the bifidobacterial population by PCR-denaturing gradient gel electrophoresis and quantitative real-time PCR. Appl Environ Microbiol 75: 965-969. [Medline] [CrossRef]

46. Martín V, Maldonado-Barragán A, Moles L, RodriguezBaños M, Campo RD, Fernández L, Rodríguez JM, Jiménez E. 2012. Sharing of bacterial strains between breast milk and infant feces. J Hum Lact 28: 36-44. [Medline] [CrossRef]

47. Heikkilä MP, Saris PEJ. 2003. Inhibition of Staphylococcus aureus by the commensal bacteria of human milk. J Appl Microbiol 95: 471-478. [Medline] [CrossRef]

48. Harmsen HJ, Wildeboer-Veloo AC, Raangs GC, Wagendorp AA, Klijn N, Bindels JG, Welling GW. 2000. Analysis of intestinal flora development in breast-fed and formula-fed infants by using molecular identification and detection methods. J Pediatr Gastroenterol Nutr 30: 61-67. [Medline] [CrossRef] 